\title{
Corrección y reescritura jesuíticas en el siglo XVIII: en torno a la obra de José Cardiel (1747-1780)
}

Jesuit correction and rewriting in the 18th century: on José Cardiel's work (1747-1780)

Fabián R. Vega*

Resumen: José Cardiel (1704-1782) escribió, entre 1747 y 1780, distintos libros sobre las misiones jesuíticas de la Provincia del Paraguay. Todos ellos constituyen reescrituras de un mismo texto de base. Por esa razón, podemos utilizarlos para analizar las modificaciones, supresiones y adiciones — es decir, las correcciones y reescrituras - entre los mismos. De esa manera, identificamos los cambios en la política de escritura jesuítica en las últimas décadas antes de la expulsión de la Compañía de Jesús de los territorios de la Corona española (1767-1768) y en las primeras después de tal hecho, esto es, en el período probablemente más crítico para los jesuitas durante la Edad Moderna.

Palabras clave: Compañía de Jesús - José Cardiel - Paraguay - Cultura escrita - Escritura edificante

Abstract: José Cardiel (1704-1782) wrote different books about Jesuit missions of the Province of Paraguay between 1747 and 1780. All of them are rewritings based on the same text. Therefore, we can use those texts to analyze alterations, eliminations and additions - i.e., corrections and rewritings - between them. Thus, we identify the changes in the politics of Jesuit writing in the last decades before the expulsion of the Society of Jesus from Hispanic territories (1767-1768) and the first years after that fact, i.e., probably the most critical period for Jesuits during the Early Modern Times.

\footnotetext{
*Facultad de Filosofía y Letras - Universidad de Buenos Aires.

E-mail: vegafabianr@gmail.com
} 
Key words: Society of Jesus - José Cardiel - Paraguay - Written Culture - Edifying Literature

Recibido: 10 de setiembre de 2016

Evaluado: 26 de noviembre de 2016 


\section{Breve introducción}

En el presente texto analizamos la escritura edificante jesuítica y, para ello, comparamos cuatro libros diferentes, firmados por o atribuidos al jesuita José Cardiel, que constituyen reescrituras de un texto de base. Estos libros son la Carta y relación de las misiones de la provincia del Paraguay (1747), la Breve relación de las misiones del Paraguay (c. 1771), "De moribus guaraniorum" (1779, traducido como "Costumbres de los guaraníes") y el Compendio de Historia del Paraguay (1780). En la primera parte del texto, sintetizamos las reglas y definiciones institucionales sobre la cultura escrita jesuítica tal y cómo fueron definidas desde el siglo XVI. A continuación, presentamos brevemente la figura de José Cardiel. Después, comparamos los cuatro libros mencionados, y clasificamos en tres grupos diferentes las modificaciones, abreviaciones, supresiones y adiciones que encontramos entre los distintos textos.

La hipótesis general de este artículo es que, aunque existe una determinada escritura jesuítica identificable como "edificante", dicha escritura no es ajena a modificaciones y variaciones que obedecen a los cambios en el contexto político, los interlocutores y los formatos de circulación de los textos. Esta hipótesis general es estudiada a partir del caso concreto de las obras de José Cardiel, de modo que esta idea global se particulariza en tres variaciones identificables, con sus correspondientes explicaciones relativas a la causa de la variación.

Estas modificaciones y explicaciones son las siguientes. En primer lugar, el cambio sobre qué se decide hacer público y "mostrable" en la escritura edificante, que se explica por la agudización de las polémicas y críticas anti-jesuíticas (a menudo centradas en las prácticas pragmáticas y de adaptación de la Compañía) y el viraje en los interlocutores de los textos, a partir de la expulsión centrados, precisamente, en dichos críticos y polemistas ilustrados. En segundo lugar, los cambios generales que requirió la preparación de una versión de los textos, que hasta entonces habían permanecido manuscritos, para convertirlo en una fuente documental pasible de ser impresa como apéndice de una Historia del Paraguay redactada por el último Provincial del territorio, Domingo Muriel. En tercer lugar, el cambio en la valoración de los conquistadores y encomenderos españoles, que se explica por la política de los Borbones españoles desde el ascenso de Floridablanca (1777) respecto de los expulsos, que implicó un intercambio de financiamiento económico por propaganda pro-española. De este modo, se demuestra que aunque los cuatro libros son reescrituras del mismo texto y participan del mismo tipo de escritura edificante, existen diferencias sustanciales entre los mismos, atribuibles a las distintas razones mencionadas.

\section{La cultura escrita en la Compañía de Jesús}

La Compañía de Jesús, fundada en 1534 y confirmada por el Papa en 1540, se caracterizó por una peculiaridad que la diferenciaba de otras órdenes: además de los tres votos que eran habituales en estas (pobreza, obediencia y castidad), los jesuitas profesaban un cuarto voto de "specialem obedientiam Summo Pontifici circa missiones", , especial obediencia al Sumo Pontífice respecto de las misiones, que estableció la evangelización a lo largo del globo como tarea prioritaria de la Compañía. En consecuencia, los jesuitas se dispersaron por las "cuatro partes del mundo" y, por esta razón, la escritu-

\footnotetext{
${ }^{1}$ Arzubialde-Corrella-García Lomas: 527, 4.
} 
ra cumplió un rol fundamental dentro de la misma. Ya en el mismo siglo XVI fueron redactados una serie de textos que contenían la política jesuítica sobre la escritura. En este sentido, los dos documentos más importantes son, por un lado, algunas cartas escritas por Juan Alfonso Polanco, secretario de Ignacio, en julio de 1547, y, por el otro, la "Formula scribendi", una formalización de las ideas expresadas por Polanco en las cartas que tuvo varias versiones a lo largo de la segunda mitad del siglo XVI.

En estas reglamentaciones, se establecía una escritura epistolar frecuente, abundante y a ritmos pautados y definidos. El primer objetivo de esa escritura era el control burocrático para sostener el funcionamiento de la orden. Así, como primera ayuda prestada por el "continuo escribir", Polanco mencionaba la unión de la Compañía de Jesús, "que anda, según su professión, sparzida en varias partes, y assi más que otras tiene necessidad de alguna comunicación con que se junte y vna, y esta es la de las continuas letras"2. Sin embargo, ese no era el único objetivo, pues en general las cartas eran útiles también para la edificación y para la confección de una imagen y una identidad propias de la Compañía, que disciplinaba los comportamientos apostólicos de los miembros de la misma. En efecto, entre otras tantas ayudas prestadas por la escritura, Polanco menciona crecer en el amor de Dios al ver actuar su Providencia, animarse a la santa emulación de las acciones retratadas y crecer la afición a la Compañía de los amigos de ella ${ }^{3}$.

¿Cómo se debía llevar adelante esta escritura que servía a distintos objetivos? El primer documento que estableció algunas precisiones al respecto es anterior a las cartas de Polanco: se trata de una carta de diciembre de 1542 firmada por Ignacio y dirigida a Pedro Favro, otro de los fundadores de la Compañía. Allí ya se definía una distinción entre una escritura mostrable y otra no mostrable, distinción que sería característica de la orden jesuítica. Al referirse a las cartas que intercambiaban las comunidades jesuíticas y sus superiores, Ignacio planteaba que debía escribirse una "carta principal" que contuviera "las cosas que muestran edificación" y que constituyera una escritura que "queda, y da siempre testimonio". De esas cartas debían eliminarse todas las "particularidades impertinentes", que sí podían incluirse en las "hijuelas", escritas "concertado o sin concierto", es decir, sin tener necesariamente buen orden o disposición.

Por lo tanto, las comunidades jesuíticas, y entre ellas las misiones, debían difundir su labor a través de una carta principal, mostrable. Ignacio realzaba, particularmente, la importancia de la corrección y la reescritura de estos textos edificantes. En efecto, en la carta mencionada describía de la siguiente manera su trabajo con los textos:

La carta principal yo la escriuo de vna vez, y después, mirando y corrigiendo, haziendo quenta que todos la han de veer, torno á escriuir ó hazer escriuir otra vez, porque lo que se escriue es aún mucho más de mirar que lo que se habla4.

Y, a continuación, agregaba:

$Y$ porque en esta parte en todo[s] veo falta, á todos escriuo esta carta, copiada, pidiendo y rogando en el Señor nuestro, es á sauer, que siempre escriuiendo la carta principal, según que arriba dije, después tornándola á remirar, la escrib-

\footnotetext{
${ }^{2}$ Polanco, 1903 [1547]: 537.

${ }^{3}$ Entre los textos que han estudiado la cultura escrita al interior de la Compañía de Jesús, pueden mencionarse: Palomo, 2005 y 2013; Friedrich, 2008; Morales, 2011; Justo, 2013; Montiel Contreras, 2014; y Hoyos Hattori, 2015.

${ }^{4}$ Ignacio, 1903a [1542]: 237.
} 
áis, ó la hagáis escribir otra vez, y assí escriuiendo dos veces, como yo hago, yo me persuado que las letras vernán más concertadas y más distintas 5 .

De modo que la reescritura resultaba central en las órdenes impartidas por Ignacio en 1542. Esa reescritura, esa corrección consistían, principalmente, en "remirar" el texto para eliminar las "impertinencias" que no podían figurar en la carta principal. Entonces, el objetivo de la reescritura era "evitar los inconvenientes del inconsiderado escribir" ${ }^{\text {, }}$ como declara el mismo Ignacio en carta a Nicolás de Bobadilla, de 1543. En este punto, cabe recordar que los textos manuscritos de la modernidad temprana, y entre ellos las cartas, tenían una naturaleza abierta, es decir, pasible de modificaciones e intervenciones sucesivas a lo largo de su proceso de elaboración ${ }^{7}$ y que en la mayoría de los discursos jesuíticos, quien cumplía el rol de "editor" contaba con una amplia libertad de supresión y manipulación ${ }^{8}$. De este modo, la noción plena de "autor", tal y como la entendemos hoy en día, probablemente no fuese aplicable a este período y a estos documentos.

A su vez, en una de las cartas, titulada "Reglas que deuen obseruar acerca del escribir los de la Compañía que están esparzidos fuera de Roma”. Polanco precisó aún más las características de la escritura jesuítica y, en particular, de las cartas principales. Así, por un lado definió con rigor los tiempos de la escritura según los espacios y cómo hacer circular las cartas. Por el otro, profundizó sobre los rasgos de la escritura mostrable. En este sentido, Polanco señalaba que los jesuitas debían escribir sobre sus actividades y atenciones, y debían evitar elogios excesivos y referencias a la política y a cuestiones que pudiesen ofender. Asimismo, "si vbiesse cosas que no pudiessen dexar de offender, y fuesse inportante auisar dellas, podríase vsar algún modo de entender vna cosa scriuiendo otra" ". Estas "Reglas..." denotan particularmente la búsqueda de una construcción retórica de la realidad, pues, por ejemplo, se señala:

Quando se scribe lo que el hombre trabaja y Dios obra en las ánimas, aunque se diga todo lo que ay, téngase aduertentia, como si todos hubiessen de ver estas letras, para que se diga en tal manera, que quien leyere vea que no se busca la propria, sino la diuina gloria y edificatión de los próximos, y hazer obedientia en scribir lo que se manda, atribuyendo á Dios enteramente lo que es suyo, que es todo lo bueno, y á sí lo proprio, que es todo lo malo ${ }^{10}$.

En efecto, el objetivo de este tipo de textos, como se ha dicho, era la ejemplificación, la edificación y la educación moral; no se fundamentaban, pues, en la oposición entre verdadero y falso. Muchas de las indicaciones reseñadas fueron trasladadas a la "Formula scribendi", que, aunque no contiene grandes novedades respecto de lo señalado, es el documento jesuítico que sirvió como reglamentación de la escritura en el largo plazo. Cabe destacar, únicamente, que en la "Formula...", cuya versión definitiva es de 1580, las "cartas principales" ya han alcanzado el formato que sería característico al

\footnotetext{
${ }^{5}$ Ibídem.

${ }^{6}$ Ibíd.: 278.

${ }^{7}$ Palomo, 2005: 64-65.

${ }^{8}$ Montiel, 2014: 8.

${ }^{9}$ Polanco, 1903 [1547], 548.

${ }^{10}$ Ibíd.: 547.
} 
interior de la Compañía de Jesús en los siglos XVII y XVIII: “cartas anuas”, es decir, enviadas por las comunidades a su superior una vez al año.

¿Por dónde y cómo circulaban estos documentos epistolares? De acuerdo a las intenciones que se desprenden de los textos y reglamentaciones mencionados, se concebía una difusión más bien restringida. En la carta de Ignacio a Nicolás de Bobadilla de 1543, se lee que: "nunca pensé que á todas [las cartas principales] las mostrárades, ni que todos se edificaran; mas pensé á pocos, y aquellos tomarían á la mejor parte" $" 11$. Asimismo, en términos generales el público receptor al que se hacía referencia estaba conformado por los propios jesuitas y por los “aficionados" a la Compañía. Las comunidades de la orden fueron, en efecto, las principales receptoras: en ellas, la difusión de estos textos era, principalmente, manuscrita, y aunque en algunas ocasiones se recurrió a la imprenta, el formato manuscrito permitía a las autoridades de la Compañía un mayor control sobre los contenidos y, también, sobre los ámbitos de circulación ${ }^{12}$. Es que, aunque las cartas principales eran en principio mostrables para individuos favorables a los jesuitas, para los superiores existía una diferencia muy clara sobre el contenido que era admisible en un texto de circulación presumiblemente restringida, como un manuscrito, y en un texto de circulación probablemente más amplia, como un impreso.

Por último, ¿cuál es la relación de estas reglamentaciones y fórmulas con los textos que nosotros trabajamos? Por un lado, los textos de Cardiel no son, exactamente, "cartas principales" o cartas anuas: dos son cartas relatorias, uno es una relación y el Compendio de Historia del Paraguay puede pensarse como un híbrido de historia y relación ${ }^{13}$. Se trata de géneros que también fueron privilegiados por los jesuitas para realizar los reportes de las misiones esparcidas por los distintos continentes. A pesar de no tratarse de "cartas principales", juzgamos que la gramática subyacente de la escritura que revelan las disposiciones de Ignacio y de Polanco también pueden aplicarse aquí en la medida en que estos géneros participaban de la misma escritura edificante destinada a ser mostrada ${ }^{14}$. Por lo demás, tanto las cartas anuas como las relaciones pueden entenderse en el marco de la construcción retórica de la realidad, característica de la modernidad temprana - de la que participaban también toda la historiografía, las crónicas y otros géneros orales o escritos-: nos referimos al uso de herramientas retóricas para realzar la función moralizadora (edificante, si queremos utilizar los términos del siglo XVI) propia de estos textos ${ }^{15}$.

Por otro lado, los textos de Cardiel fueron escritos en el siglo XVIII. Entre el siglo XVI y el XVIII, la escritura jesuítica no se mantuvo siempre igual a sí misma: Morales, por ejemplo, ha demostrado la evolución que se operó en la historiografía y la

\footnotetext{
${ }^{11}$ Ignacio, 1903b [1543], 280.

${ }^{12}$ Palomo, 2005: 73-77.

${ }^{13}$ La carta relatoria, propia de los contactos ultramarinos de la modernidad temprana, narraba con detalle una experiencia, y en ese sentido era diferente del género epistolar ordinario, aunque desde luego combinaba los rasgos de este género y de la relación. La relación era una narración fundamentada en el testimonio de vista y la "historia" una narración escrita por letrados, basada en la sucesión temporal pero no constreñida por la misma. Véase Mignolo, 1992: 59-69 para cartas relatorias; 70-75 para relaciones; y 7598 para la historia).

${ }^{14}$ Sobre el vínculo entre cartas anuas y relaciones, ver Friedrich, 2008: 6.

${ }^{15}$ Chinchilla-Correa-Mendiola, 2008. Actualmente, el equipo de Perla Chinchilla y sus colaboradores en la Universidad Iberoamericana se encuentra preparando un Lexicón de formas discursivas cultivadas por la Compañía de Jesús, el cual arrojará mayor luz sobre las características puntuales de los distintos tipos de textos que pueden incluirse dentro de la escritura edificante jesuítica.
} 
acentuación, en primera instancia, del ocultamiento de cualquier conflicto o problema interno a la Compañía y, a continuación, de la "escritura obsidional", es decir defensiva, frente a los ataques provenientes del exterior ${ }^{16}$. Son fenómenos propios de variaciones más generales dentro de la auto-representación jesuítica. No obstante, esos cambios, precisamente por acentuar el aspecto defensivo de la escritura, no modificaron el carácter mostrable y edificante definido en los párrafos anteriores, que, por lo tanto, resulta también aplicable a la relación, la historia y las cartas relatorias de Cardiel en el siglo $\mathrm{XVIII}^{17}$.

\section{José Cardiel y su escritura}

José Cardiel nació en 1704 en Laguardia, que hoy en día forma parte de la comarca de La Rioja Alavesa en la comunidad autónoma del País Vasco. Era hijo de un médico y el menor de tres hermanos, todos los cuales ingresaron a la Compañía de Jesús. Cardiel lo hizo en 1720; realizó el noviciado en Villagarcía de Campos (Valladolid) y cursó estudios en Medina del Campo con el famoso predicador Pedro de Calatayud (1698-1773), a quien dirigió formalmente dos de los tres documentos con que trabajamos en este texto y con quien mantuvo correspondencia a lo largo de toda su vida. En 1729 llegó a Buenos Aires — habiéndose ya ordenado como sacerdote-, y arribó a las reducciones de guaraníes en 1731. Por tanto, se encontraba en estas reducciones cuando estalló la segunda etapa de la revuelta comunera de Asunción (1721-1735), iniciada en 1731. Cardiel permaneció entre los guaraníes hasta 1743.

Entre ese año y 1754, pasó por los colegios de Corrientes, Santa Fe y Asunción, por las misiones entre los mocovíes y abipones del Chaco, entre los charrúas y entre los pampas y serranos y por misiones interiores de españoles (criollos) en Santa Fe. También participó en dos viajes hacia la Patagonia, el primero en barco junto con José Quiroga y a través de las costas (1745-1746) y el segundo en un intento, que no logró cruzar el río Colorado, por alcanzar por tierra el estrecho de Magallanes (1748). A partir de 1754 se encontró nuevamente en las reducciones de guaraníes, entre quienes permaneció hasta la expulsión de la Compañía de los dominios hispánicos (1767-1768). Estando allí, asistió a, por lo menos, los acontecimientos finales de la Guerra Guaranítica (17521756), que enfrentó a los ejércitos español y portugués contra los guaraníes alzados en oposición al traslado de siete reducciones estipulado por el Tratado de Madrid (1750).

En ese conflicto, Cardiel jugó un rol ambiguo. En primer lugar, consideró al Tratado como una injusticia, y escribió cartas denunciándolo. Por esta razón, fue reducido a obediencia al interior de su orden y debió guardar penitencia, después de lo cual contribuyó a la pacificación de los guaraníes rebeldes y llegó a ser capellán del ejército hispano-portugués. Posteriormente, estableció una relación de cercanía con el gobernador de Buenos Aires y futuro virrey Pedro de Cevallos (1715-1778), de quien se convirtió en

\footnotetext{
${ }^{16}$ Morales, 2007: 28-42. Sobre las historias escritas a partir del generalato de Aquaviva, véase también Justo, 2013.

${ }^{17}$ Las regulaciones sobre la escritura concernían también a textos administrativos, en principio no mostrables. En un Libro de Preceptos de las misiones de guaraníes de mediados del siglo XVIII, se propone en los memoriales "atajar el pernicioso desorden de referir, o escribir los delitos de los indios, debiendo hablar de lo bueno, que hay, y callar lo malo; y no deje al que hallare sin castigo" (AGN, Sala VII - Colección Biblioteca Nacional, , 140). Esta referencia ha sido analizada por Wilde (2009: 42-47) en el marco de una caracterización sobre los documentos y la escritura jesuítica concernientes a las misiones de guaraníes.
} 
confesor y con quien participó, como capellán del ejército, en la campaña militar a Colonia del Sacramento (1762-1763). Todavía se encontraba en las reducciones de guaraníes cuando fue decretada la expulsión de la Compañía de los dominios hispánicos, en 1767. Viajó a España, a donde llegó en 1769, y luego se estableció, junto a otros jesuitas expulsos del Paraguay, en Faenza, Italia, en donde se dedicó, fundamentalmente, a la escritura y la cartografía. Falleció en esa ciudad en $1782^{18}$.

La obra escrita de Cardiel es numerosa, por lo que no podemos reseñarla aquí en profundidad $^{19}$. Si hacemos a un lado los escritos de escasa extensión, puede decirse que Cardiel escribió dos tipos de obras. Por un lado, algunos diarios y relaciones de viaje: existe, en efecto, un Diario de un viaje a la costa de la Mar Magallánica, que es una reescritura firmada por Pedro Lozano a partir de observaciones de Quiroga y Cardiel, y un Diario del viaje y misión al Río del Sauce por fines de marzo de 1748. Por el otro, una serie de textos sobre o en defensa de las misiones jesuíticas, que en la mayoría de los casos pueden considerarse, hasta cierto punto, la reescritura de un mismo texto. Ordenados por fecha de escritura o publicación, los escritos son los siguientes: la Carta y relación de las misiones de la Provincia del Paraguay (escrito en 1747), Misiones del Paraguay. Declaración de la verdad (escrito en 1758 como respuesta a la crítica antijesuítica del marqués de Pombal), Breve relación de las misiones del Paraguay (c. 1771), "De moribus guaraniorum" y "Prestigiae de Regno Paraguaico discussae. Fusioris operae compendium" (impresos en 1779 como apéndices a la continuación latina de la historia de Charlevoix escrita por Domingo Muriel; los títulos traducidos por Pablo Hernández son: "Costumbres de los guaraníes" y "Deshácense los encantamientos del Reino del Paraguay. Compendio de una obra más extensa"; este último texto es una respuesta, en forma de diálogo, al libro anti-jesuítico de Ibáñez de Echavarri) y, por último, Compendio de la Historia del Paraguay (escrito en 1780 y descubierto en la década de 1980).

\section{Correcciones y modificaciones en los textos}

Los textos que comparamos son la Carta y relación de las misiones de la provincia del Paraguay (1747), la Breve relación de las misiones del Paraguay (c. 1771), "De moribus guaraniorum" (1779) y el Compendio de la Historia del Paraguay $(1780)^{20}$. Los cuatro constituyen la reescritura de un texto de base, probablemente la misma Carta y relación... de 1747. Aunque los cuatro constituyen relaciones o escritos parcialmente relatorios sobre el mismo espacio geográfico, la comparación no puede hacerse oración por oración, dado que en algunos casos hay cambios sustanciales. Sin embargo, en términos generales puede establecerse una correspondencia entre los capítulos de cada una de las relaciones, pues su referente es exactamente el mismo y a menudo la secuencia narrativa que guía el relato también ${ }^{21}$.

\footnotetext{
${ }^{18}$ Para la reconstrucción biográfica de Cardiel, véase: Furlong, 1953: 7-53; y Caraman, 2001: 654-655.

${ }^{19}$ ver Furlong, 1953: 54-109 para mayor detalle.

${ }^{20}$ Por razones de espacio y de claridad analítica y expositiva, se ha optado por dejar una de las reescrituras de ese texto base: Misiones del Paraguay. Declaración de la verdad (1758). Este libro sólo parcialmente es un escrito relatorio basado en el mismo texto de base que los otros, y la sección comparable es, en ese sentido, de escasa extensión. Prima en él el componente polémico.

${ }^{21}$ Sobre la correspondencia entre los capítulos de los distintos libros, véase el anexo (Cuadro 1, Cuadro 2).
} 
Los dos primeros textos y el Compendio... circularon de modo manuscrito. La Carta y relación... aparece firmada "Buenos Aires, Diciembre 20 de 1747"22, de modo que fue escrita entre la participación de Cardiel en la misión de pampas y serranos, y su viaje por tierra hacia la Patagonia.

La Breve relación... carece de fecha, pero Calatayud, en su Tratado del Paraguay, escribió: [E]n este año de 1771 he recibido, leído y se ha leído con singular aprobación de las provincias de Castilla y Paraguay y remitido á Roma una copia fiel, la Relación que formó el P. Josef Cardiel $^{23}$. En la dedicatoria de la Breve relación..., que luego citaremos, se dice que esta fue encargada por Calatayud, probablemente para la escritura de ese Tratado... Es evidente que se trata del mismo texto, por lo que podríamos fechar su escritura en 1770 o 1771.

En cuanto al Compendio..., no aparece firmado por Cardiel, sino por el anagrama de "José Darceli", con el que se intentó ocultar la identidad jesuítica de Cardiel para evitar prejuicios sobre la lectura del texto, a pesar de que no pueden quedar dudas al respecto. Mariluz Urquillo, que descubrió el manuscrito a fines del siglo XX, lo fechó en torno a $1780^{24}$.

Por último, "De moribus..." es el único de los tres que fue impreso. Se trata de una traducción latina reducida de la Breve relación..., y fue publicada como apéndice documental del libro Historia Paraguajensis Petri Francisci-Xavierii de Charlevoix. Este libro, impreso en Venecia en 1779, contenía, además de los capítulos escritos por Charlevoix, una continuación de la mano de Domingo Muriel, y un apéndice documental que incluía "De moribus...", firmado como "A. I. C.". Por el parecido con la Breve relación..., esta firma ha sido identificada, ya por Furlong, como una referencia a José Cardiel (I. C.; correspondiendo la I latina a nuestra J) ${ }^{25}$.

Entre los cuatro textos existen diferencias: supresiones, modificaciones, reducciones, adiciones. Agrupamos estas diferencias en tres categorías. En primer lugar, las diferencias en cuanto a aspectos que, dada las modificaciones y violentos virajes del contexto político y religioso desde 1747 hasta 1779 —en especial la expulsión de los jesuitas de los dominios hispánicos en 1767-1768 - , pasaron a percibirse como impertinencias que no contribuían a la representación escrita de las misiones del Paraguay como un paraíso utópico. En segundo lugar, aquellas modificaciones derivadas de la preparación de uno de los textos para ser impreso. En tercer lugar, las modificaciones relacionadas con la política de financiamiento económico de los Borbones después de la expulsión y, sobre todo, después del ascenso de Floridablanca (1777) y su campaña propagandística pro-española.

Cabe aclarar tres cuestiones. Primero, a fin de analizar precisamente la reescritura jesuítica, este artículo sólo se centra en aquellas referencias que existen a lo largo de los cuatro textos, razón por la cual nos veremos obligados a no centrarnos puntualmente en lo que se dice sobre la Guerra Guaranítica (1752-1756) o sobre la expulsión de los jesuitas de los territorios hispánicos $(1767-1768)^{26}$. Segundo, no se analizan la totalidad

\footnotetext{
${ }^{22}$ Cardiel, 1953 [1747]: 213.

${ }^{23}$ Cardiel, 1913 [c. 1771]: 513.

${ }^{24}$ Mariluz Urquillo, 1984: 7-36.

${ }^{25}$ Furlong, 1953: 82.

${ }^{26}$ Esto no significa que aspectos sólo tratados en algunos de los textos carezcan de importancia para los tópicos trabajados aquí. Por ejemplo, la Breve relación... contiene alusiones importantes en polémica con
} 
de las diferencias, lo cual resulta imposible dado que se trata de cuatro diferentes, aunque basados en un texto de base, y no de cuatro versiones distintas del mismo texto. El artículo se centra únicamente en las modificaciones que se juzgan como analíticamente relevantes, que son, sobre todo, aquellas relacionadas con una dimensión geopolítica o religiosa. Por último, como se ha dicho anteriormente, es conveniente recordar que no puede aplicarse a estos textos una noción tradicional de "autor"; para empezar, la presencia constante de un copista ya fragmenta esa figura, y en ocasiones puntuales se deberán resaltar intervenciones escriturales y editoriales ajenas a la pluma de Cardiel.

\section{a) De la adaptación a la utopía}

Existen algunas alusiones a la práctica del catolicismo en los espacios misionales en la Carta y relación... de 1747 que son modificadas o suprimidas en los otros tres textos. Aquí citaremos todos los fragmentos en primer lugar y realizaremos una explicación y contextualización posteriormente. Para empezar, al comienzo de la explicación del establecimiento de los jesuitas entre los guaraníes, en el capítulo II de la Carta y relación..., puede leerse una larga descripción de la "calidad" y el "entendimiento" de estos indígenas. Después de una caracterización tradicional de los mismos como salvajes y antropófagos antes de la llegada de los españoles ${ }^{27}$, y luego de haber declarado que "[e]1 entendimiento y discurso, [es] muy débil y defectuoso", leemos:

En las confesiones nos sucede [que declaran] cada día sí y no a una misma cosa, y inmediatamente, y en materia grave: conocemos que no es así por malicia, sino por estupidez de entendimiento: a la manera que a un niño, si le preguntan: ¿Sabes mentir? Responde Sí, y preguntando segunda vez responde No; y cuántas veces le pregunten responde ya Sí, ya No. Por lo cual no nos valemos del común sentir de los teólogos europeos, que dicen se debe guiar el confesor por lo que el penitente dice: que erraríamos mucho en ello. Del genio y condiciones del penitente y de las circunstancias de la confesión, formamos juicio de la verdad ${ }^{28}$.

Es decir, como consecuencia del entendimiento "defectuoso" de los guaraníes, los jesuitas ven necesario modificar el sacramento de la confesión respecto "del común sentir de los teólogos europeos". En el capítulo III, sobre gobierno religioso, se encuentra un fragmento similar:

Las confesiones en vísperas de días solemnes, en que se confiesa mucha gente, son las que cuestan más que todo, porque para cada día de éstos se suelen confesar muchos centenares, que llevan toda la mañana, y parte de la tarde. Empiezan a confesar 4 y 5 días antes de la fiesta (por no poder dar abasto de otro modo) dos de los confesores; como son confesiones de gente tan ruda y en idioma extraño, difícil y no del todo bien entendido sino de los muy antiguos, cuestan (la materia de) dos horas de confesiones lo que entre Españoles (la materia de) 8. Un alivio tenemos en ellos, y es que ningún indio ni india se encuentra que tenga escrúpulos, y raro que cuente historias. Todo nace de su corta capacidad. Pero

el mito anti-jesuítico del supuesto rey Nicolás (un rey jesuita o indígena que la Compañía habría erigido en el Paraguay, independiente de los poderes coloniales). Respecto de este tópico, véase la interpretación de Becker (1987), que resalta la participación jesuítica en el nacimiento del mito.

${ }^{27}$ Cardiel, 1953 [1747]: 125

${ }^{28}$ Ibíd.: 127. 
como insinué algo en el núm. 26 [se refiere al párrafo citado anteriormente], es cosa que hace sudar el ver que a una misma cosa responden ya sí, ya no; el no poder averiguar si la materia llegó a pecado grave, por no saber dar razón de lo que preguntan; el no poder saber, por más que le pregunten, si el pecado que dice calló mucho ha, lo confesó ya en otras confesiones; y finalmente, la duda de su dolor por la insensibilidad que muestra a las más fervorosas persuasiones e invectivas $^{29}$.

Se reitera aquí la misma información que en el fragmento anterior, pero se agrega la incapacidad, por parte del sacerdote, de reconocer la contrición en el penitente, el "dolor" por el pecado cometido, entre otras cuestiones. Los dos fragmentos citados, entonces, aluden a las peculiaridades del sacramento de la confesión en las misiones de guaraníes. Ahora bien, ¿qué dicen los otros textos sobre estas peculiaridades? En el capítulo III de la Breve relación..., correspondiente al II de la Carta y relación..., se encuentra la misma descripción sobre el salvajismo y la antropofagia de los guaraníes precoloniales $^{30}$, pero nada se dice sobre el entendimiento en general y sobre las consecuencias de este en el sacramento confesional en particular. Al contrario, se aclara apologéticamente que "causaba grande admiración ver á los que antes eran sangrientas fieras, tan mudados en lo racional y cristiano"31. Algo parecido, aunque con menos énfasis, se dice en el capítulo II de "De moribus...", una referencia al entendimiento "limitado" de los guaraníes ${ }^{33}$, pero todas las referencias al sacramento confesional han sido eliminadas del libro. A su vez, en la Breve relación... la sección sobre las confesiones durante las fiestas de precepto (capítulo VI, sobre gobierno religioso) señala lo siguiente:

Todos los días hay esas tareas de confesiones de precepto, que suelen llegar á tres mil, y en pueblos grandes á cuatro y cinco mil. Y como se confiesan muchos en cada fiesta por devoción, suelen llegar al año á diez mil: lo que se sabe por las formas de la comunión, que se apuntan. Así sucede en Yapeyú y en otros, que en los años pasados casi le igualaban en lo grande. Este es el gobierno, observancia regular, y ministerios de los Padres. Ya es tiempo que volvamos á los indios ${ }^{34}$.

El fenómeno explicado es el mismo que en la Carta y relación..., pero los problemas de la confesión sui géneris en las misiones de guaraníes, las dificultades por reconocer el dolor de los pecados y las confusiones entre afirmación y negación han desaparecido $^{35}$. En síntesis: en la Carta y relación... existen alusiones a la peculiaridad de la administración del sacramento de la confesión entre los guaraníes, peculiaridad derivada de su "entendimiento" — según la mirada jesuítica- y con consecuencias como no poder reconocer el dolor interno por los pecados o si los pecados efectivamente se habían cometido o no. Esas alusiones no se encuentran en los otros textos.

\footnotetext{
${ }^{29}$ Ibíd.: 135-136.

${ }^{30}$ Cardiel, 1913 [c. 1771]: 518.

${ }^{31}$ Ibídem.

${ }^{32}$ Cardiel, 1779: 561.

${ }^{33}$ Ibíd., 1984 [1780]: 95. Corresponde al capítulo 8 del libro.

${ }^{34}$ Ibíd., 1913 [c. 1771]: 555.

${ }^{35}$ Una mayor reducción se observa en el capítulo correspondiente de "De moribus..." (Cardiel, 1779: 570), mientras que, como se ha dicho, no hay alusiones a la confesión en el Compendio...
} 
Las supresiones y modificaciones se aplican también a otras referencias a la práctica religiosa contenidas en la Carta y relación... Aquí nos limitaremos sólo a un ejemplo más, esta vez referido no a las misiones de guaraníes, sino a la forma más adecuada de evangelizar en las misiones con indígenas nómades - considerados más difíciles de cristianizar-. En la Carta y relación... se lee:

Es preciso disimular mucho a los principios con sus borracheras, hechicerías, etc., sin instarles ni molestarles porque las dejen. Si esto se hace, se enojan y retraen y aun vuelven a su pasada vida y tierras, y retraen a los demás de que vengan (...) La medicina se debe aplicar en tiempo y sazón, cuando ha de hacer provecho: fuera de su tiempo, aunque ella sea muy buena, es veneno ${ }^{36}$.

Y, a continuación, se relata una anécdota ilustrativa: un jesuita cuestionó fuertemente que una hechicera asistiera, con curaciones supersticiosas, a un enfermo. Por esa razón, relata Cardiel, la misión se echó a perder. Cardiel prefería, en cambio, adaptarse a las costumbres de los indígenas evangelizados. Ahora bien, ¿cómo se relata la evangelización a los indígenas nómades en la Breve relación... de 1771? Aquí no se mencionan la aceptación de la borrachera ni de la hechicería. En cambio, puede leerse que:

Con estos medios, mucha paciencia, sufrimiento, tesón, y espera y muchos gastos, fueron entrando en vida racional y cristiana: de suerte que á los tres años ya entraron a hacer sementeras de común y los vicios reinantes se quitaron del to$\mathrm{do}^{37}$.

De los dos ejemplos citados aquí, entonces, uno alude a la modificación del sacramento de la confesión dentro de las misiones de guaraníes y el otro a la aceptación de la pervivencia (en principio temporal) de costumbres locales en las misiones a indígenas nómades. Ambas referencias fueron eliminadas en las posteriores revisiones del texto. ¿Por qué?

Antes que nada, conviene entender el significado de las dos alusiones en el marco del modo de proceder jesuítico, que por razones espaciales aquí no podemos analizar en detalle sino sólo presentar. En contextos de misión, y en comparación con otras órdenes religiosas, el modo de proceder jesuítico era particularmente pragmático. Esto significaba que, en función de su objetivo fundamental (la conversión para la salvación, de acuerdo a los parámetros católicos), los jesuitas podían aceptar modificaciones de las prácticas y ritos del cristianismo, pervivencias de costumbres pre-cristianas, diversos tipos de mestizajes, etc. Quizás el concepto que mejor englobe el amplio arco de políticas de pragmatismo y tolerancia que los jesuitas implementaron en el plano misional sea el de accomodatio. La idea de "acomodación" puede rastrearse en textos del propio Ignacio; de acuerdo a la formulación discursiva de esta idea, los jesuitas podían aceptar la pervivencia de costumbres que se juzgaban como "civiles", es decir, carentes de contenido religioso o idolátrico ${ }^{38}$. La aplicación más conocida del principio de accomodatio

\footnotetext{
${ }^{36}$ Cardiel, 1953 [1747]: 197.

${ }^{37}$ Ibíd., 1913 [c. 1771]: 602. La explicación de las misiones a indígenas diferentes a los guaraníes ha sido suprimida por completo en "De moribus...", aunque es un tópico tratado en los capítulos añadidos por Muriel a la Historia de Charlevoix. En cuanto al Compendio..., aunque las misiones a indígenas nómades son efectivamente explicadas, poco se dice sobre los métodos de evangelización, y se declara simplemente que "en estos últimso años se han reducido a pueblos y a cristiandad muchos millares de indios vagabundos y feroces" (Ibíd., 1984 [1780]: 45).

${ }^{38}$ Véase: Rubiés, 2005; Corsi, 2008: 34-51; Zupanov, 2011; Ginzburg, 2014; Wilde, en prensa, a.
} 
se dio en la misión en China del jesuita Mateo Ricci (1552-1610) y sus sucesores, que aceptaron aspectos del confucianismo y, en especial, que los católicos chinos mantuviesen lo que los críticos de esta estrategia juzgaban un culto a los muertos, a través de la figura de Confucio. Entre los dos ejemplos que citamos de la Carta y relación... de 1747, la aceptación de costumbres locales en connivencia con la evangelización católica resulta particularmente notoria en el caso de las misiones a indígenas nómades.

A su vez, la alusión a la modificación del sacramento confesional se inscribe, también, en el modo de proceder pragmático de los jesuitas, pero con un matiz relacionado con la teología moral. La teología moral es la rama de la teología centrada en los principios morales de los actos humanos y, por tanto, en el pecado, la penitencia, el perdón, etc. A su vez, en el marco de las múltiples corrientes de esta rama de la teología, los jesuitas tendieron a adherir a aquellas doctrinas casuísticas, esto es, basadas antes en casos particulares que en principios generales. Dentro de la casuística, el probabilismo fue una de las corrientes más importantes ${ }^{39}$. Según el probabilismo, en caso de duda moral frente a una determinada acción — es decir, duda sobre si esa acción constituía o no pecado, o constituía pecado mortal o venial-, bastaba cualquier argumento, cualquier opinión de un doctor de la Iglesia o tratadista para adjudicar a esa acción la calificación menos grave. Así pues, una sola opinión "probable" bastaba, incluso aunque no fuera la más probable, para rechazar calificar una acción "sospechosa" como pecado. De este modo, se promulgaban "unos principios de actuación que reducían la incidencia del pecado, facilitando el acceso a la salvación" 40 , así como también un "perdón fácil" en la práctica del sacramento de la confesión ${ }^{41}$. Respecto de este perdón fácil, un punto de cuestionamiento del probabiliorismo y el rigorismo respecto del probabilismo, según Jean Delumeau ${ }^{42}$, concernía a la contrición o dolor por los pecados cometidos. Al respecto, dos teólogos franceses del siglo XVII declaraban que: "[1]a confesión es nula y sacrílega cuando el penitente no tiene un dolor suficiente de sus pecados, aunque éstos sean veniales", y respecto de la confesión de pecados "en que se volverá a caer" por falta de dolor decían:

[E]l sacrilegio que esa persona cometería en ese caso sería pecado mortal, y no sólo venial, aunque su confesión sólo sea de pecados veniales. En efecto, cometería una irreverencia notable en esta ocasión contra el sacramento volviéndolo nulo, y haciendo que las palabras de la absolución, que el confesor pronunciaría al darla, fueran nulas y de ningún efecto ${ }^{43}$.

De acuerdo al fragmento de 1747 que fue eliminado posteriormente, en las misiones de guaraníes existía la posibilidad de que el sacerdote otorgase la absolución sin reconocer la contrición del penitente. Además de que, como es evidente, esto manifestaba una falta de internalización, entre los guaraníes, de uno de los fundamentos del

\footnotetext{
${ }^{39}$ Rico-Callado, 2012: 36.

${ }^{40}$ Ibíd. 37.

${ }^{41}$ En las misiones de guaraníes, quizás el caso más palmario de aplicación del probabilismo a la resolución de una problemática precisa haya sido el de los matrimonios de indígenas. Entre estos indígenas, existían generalizadas prácticas que los europeos juzgaban como incesto y poligamia. Los jesuitas juzgaron la validez de los matrimonios indígenas caso por caso y en función de un razonamiento probabilista. Esto llevó a que, muchas veces, se aceptara la permanencia de uniones en grados prohibidos por la Iglesia. Respecto de este problema, véase: Wilde, 2009: 132-137; e Imolesi, 2004 y 2011.

42 Delumeau, 1992: 123-129.

${ }^{43}$ Ibíd.: 127.
}

96 Fabián R. Vega. Corrección y reescritura jesuítica en el siglo XVIII ... 84-110. 
catolicismo, aquí lo importante es que una práctica como la descripta por Cardiel probablemente no hubiese sido aceptada por teólogos rigoristas como los citados. En este sentido, parece posible vincular esas peculiaridades de la confesión entre los guaraníes con el pragmatismo y relativismo del casuismo en aspectos morales y con la política de adaptación de las normas a las situaciones concretas característica de la Compañía de Jesús.

De hecho, la misma Carta y relación... de 1747 incluye una referencia a la resolución de dudas morales, basada desde luego en el casuismo y el probabilismo, aunque, en este caso, sin relación con el sacramento de la confesión. Allí se señala que, frente a una peste por la que morían muchas mujeres embarazadas, se difundió la práctica de utilizar un trago de vino para provocar un aborto y, de ese modo, bautizar a la criatura nacida en los pocos segundos de vida que tenía (la madre, tras el aborto, también moría). De ese modo, desde el punto de vista jesuítico, dos almas eran salvadas, mientras que en caso de no realizar el aborto, sólo podía salvarse el alma de la madre (madre y feto morían de todas formas). Al respecto, se dice:

Excitóse la duda de si esto era directe procurare abortum, que aunque fuese por tan santo fin, está condenado el que sea lícito [es decir, es pecado], por ser intrinsece malum (...) Fue a la Universidad de Córdoba la controversia (...) respondieron los Doctores que atentas las circunsztancias, no era directe procurare abortum, non erat intrinsece malum, y por consiguiente erat licitum [no era pecado $]^{44}$.

Esta alusión a una práctica tan peculiar - y su aceptación en el marco de los canales de legitimación moral al interior de la Compañía de Jesús ${ }^{45}$ - fue suprimida en los dos textos posteriores.

Ahora bien, si adaptaciones y pragmatismo eran parte de la idiosincrasia jesuítica, ¿por qué las alusiones terminaron siendo suprimidas en las versiones posteriores? Para responder esta pregunta, debemos referirnos a las modificaciones de la escritura jesuítica en la segunda mitad del siglo XVIII, y entre los jesuitas del Paraguay, específicamente después de la expulsión de los dominios hispánicos en 1767-1768 ${ }^{46}$. Los jesuitas sufrían, en este contexto, el impacto cada vez mayor del "anti-jesuitismo". Desde fines del siglo XVII, una parte importante de las críticas apuntaban a la política de $a c$ comodatio y su modo de proceder pragmático, especialmente en el conocido debate sobre los ritos chinos, y de acuerdo a Pavone esas críticas pasaron agresivamente del interior de las congregaciones a la exterioridad de las imprentas en la década de $1730^{47}$. En este debate, las adaptaciones de Mateo Ricci y sus sucesores al confucianismo, al presunto culto a los muertos y a otras costumbres locales fueron duramente cuestionadas como formas de pervivencia del gentilismo y la idolatría, y finalmente recibieron una condena papal en 1704, ratificada en 1742. Por lo tanto, a lo largo de todo el siglo

\footnotetext{
${ }^{44}$ Cardiel, 1953 [1747]: 188, subrayados del texto.

${ }^{45}$ El pragmatismo jesuítico debe inscribirse en las características de la toma de decisiones en los niveles inferiores de la Compañía de Jesús, de la cual el ejemplo citado del aborto y su legitimación moral es un ejemplo palmario. Los estudios más recientes al respecto (en especial Fechner, 2014, 2015) han deconstruido la imagen tradicional de una Compañía fuertemente centralizada en la que el Prepósito General o el Provincial serían figuras omnipotentes, y han enfatizado en cambio la descentralización y la autonomía de las escalas inferiores de la orden.

${ }^{46}$ Wilde, en prensa, $b$.

${ }^{47}$ Pavone, 2014: 43.
} 
XVIII, la política pragmática de adaptación de los jesuitas — que se hace visible en las alusiones del texto de 1747- estuvo fuertemente en cuestionamiento. Ahora bien, en términos generales, la Compañía de Jesús "extremó sus procedimientos e intentó neutralizar a toda costa cualquier crítica" después de la expulsión de Portugal (1759) y de Francia $(1762)^{48}$. De hecho, desde el campo anti-jesuítico hispánico, se dio impulso oficial a las críticas una vez que ya se había producido la expulsión (1767-1768), a manera de justificación ${ }^{49}$. Por lo tanto, todo parece indicar que entre el texto de 1747 y los otros (c. 1771, 1779, 1780) se asiste a un acrecentamiento de la polémica anti-jesuítica y de la defensa de la Compañía frente a los ataques externos.

A su vez, la comparación entre el texto de 1747 y los posteriores respecto de las prácticas religiosas demuestra una política muy clara de reescritura: todas y cada una de las alusiones a las adaptaciones frente a la alteridad — que, en última instancia, demostraban una incapacidad jesuítica para establecer un dominio sólido y automático entre los indígenas - fueron sistemáticamente suprimidas y ocultadas. Es decir, después de que la Compañía extremase sus procedimientos para neutralizar las críticas, esas referencias pasaron a ser consideradas "impertinencias" en el sentido definido para la escritura edificante en la primera sección de este artículo. Y por lo tanto, acorde con la práctica recomendada por Ignacio sobre "mirar y remirar" los textos para corregirlos y reescribirlos, debieron ser eliminadas. Las correcciones, entonces, no sólo fueron producto de que los textos de 1771 a 1780, preparados en Europa, hayan pasado por una mayor cantidad de "filtros" que la Carta y relación... de 1747 (la propia naturaleza de esos textos implicaba que eran actualizaciones, reescrituras de ese texto de base ${ }^{50}$ ), sino fundamentalmente por la modificación del contexto político para la Compañía de Jesús y la variación de los interlocutores de sus textos. En este último sentido, debe destacarse que después de la expulsión muchos textos jesuíticos comenzaron a polemizar con sus críticos ilustrados $^{51}$. Los cuatro textos son edificantes y mostrables, según las categorías de la primera sección de este artículo. Pero, como se ha dicho, los interlocutores tradicionales de los textos edificantes jesuíticos eran los propios miembros de la orden, mientras que, en el marco de la polémica posterior a la expulsión, esta situación parece haberse modificado. De modo que puede decirse que la frontera entre lo discursivamente edificante y mostrable, por un lado, y lo impertinente y no mostrable, por otro, era móvil y porosa, y la modificación del contexto fue fundamental al respecto ${ }^{52}$.

\footnotetext{
${ }^{48}$ Alabrús, 2010: 226.

${ }^{49}$ Neumann, 2016: 45.

${ }^{50}$ No obstante, el texto de 1747 también había pasado por un “filtro". Una sección (Cardiel, 1953 [1747]: 182-187) del capítulo IX, de contenido polémico, se diferencia estilísticamente del resto del texto, y la segunda persona retórica que utiliza no corresponde con la usada en el resto del libro, dirigida a Pedro de Calatayud. Aquí se lee: "Digo, pues, que yo tengo más de 17 años de Religión; que he hecho, no sólo las 17 profesiones que decís, sino más de 27; que ha más de diez años que hice la última del $4^{\circ}$ voto: y que he sido Superior ya dos veces" (Cardiel, 1953 [1747]: 184). Cardiel nunca fue provincial, y en diciembre de 1747, momento de escritura del texto, lo era Bernardo Nusdorffer, que también lo había sido entre 1734 y 1739 (Hernández, 1913: 614-615; McNaspy, 2001: 2842). Por lo tanto, esas páginas, cuyo contenido no reaparece en los otros libros, fueron añadidas por Nusdorffer, quien forzosamente, entonces, debió revisar el resto de la carta relatoria. Como ya se ha indicado, la noción de "autoría" debe aplicarse con cautela a este tipo de textos.

${ }^{51}$ Wilde, en prensa, $b$.

${ }^{52}$ Por lo demás, es posible que la política del Provincial del Paraguay Domingo Muriel (1770-1773) también influyese respecto de estas modificaciones. Después de la expulsión, los jesuitas de esta Provincia reencontraron una vía posible para (re)construir su identidad en la historia de las misiones y reducciones,
} 


\section{b) El paso a la imprenta}

"De moribus guaraniorum" es una reescritura directa de la Breve relación... de c. 1771 (mientras que el Compendio..., aunque posterior a "De moribus...", se basa más en la Breve relación... que en el texto latino). Hasta aquí no se ha diferenciado en mayor medida del mismo. Sin embargo, existen algunas modificaciones, que podrían ser interpretadas como meros cambios estilísticos pero que tienen relevancia para el estudio de la cultura escrita jesuítica y del uso de los documentos relatorios en el marco del género historiográfico. Observemos, entonces, tres grandes diferencias.

La primera se encuentra en la presencia/ausencia de dedicatoria. A pesar de su título, la Breve relación... de c. 1771 se presenta, en realidad, como una carta relatoria. Comienza, en efecto, de la siguiente manera:

\section{Mi Muy Venerado P. Pedro De Calatayud:}

Uno de los principales puntos que V. R. me encarga, es una relación universal de las decantadas Misiones del Paraguay, por haber yo habitado en ellas dos veces (...).

\section{Haré lo que pudiere para satisfacer á V. R., á quien tanto debo ${ }^{53}$.}

Una dedicatoria similar, aunque más extensa, se encontraba en la Carta y relación... de $1747^{54}$. Sin embargo, en "De moribus..." la dedicatoria se ha eliminado, y el texto se inicia directamente con el primer capítulo, que comienza sin presentación: "Primus Hispanorum ad Flumen Argenteum aditus incidit circa annum 1530",55.

La segunda diferencia es que en "De moribus..." se eliminaron todas las alusiones a la Guerra Guaranítica, a la que se dedicaban varias secciones en la Breve relación... de c. 1771, y varios capítulos en el Compendio... Como se ha dicho con anterioridad, "De moribus..." forma parte del apéndice documental de la continuación de la historia de Charlevoix escrita por Domingo Muriel. En este libro, las referencias a la Guerra Guaranítica sólo se eliminaron respecto de "De moribus..." y no de otros textos. Por ejemplo, en "Prestigiae de Regno Paraguaico discussae. Fusioris operae compendium" ("Deshácense los encantamientos del Reino del Paraguay. Compendio de una obra más extensa"), también escrito por Cardiel y que forma parte del apéndice, efectivamente existen alusiones al conflicto bélico. Muriel también otorga amplio espacio a la Guerra Guaranítica en sus añadidos a Charlevoix. Asimismo, fueron eliminadas todas

su gran orgullo. Esto determinó una exacerbación apologética respecto de ese espacio, una de cuyas manifestaciones, más tardía, fue el libro de José Manuel Peramás De Administratione guaranica comparate ad Republicam Platonis commentarius (traducido como La República de Platón y los guaraníes) de 1793, que comparaba las reducciones con la república ideal platónica. En el marco de esta exacerbación apologética, promovida políticamente desde arriba y condicionada por la búsqueda de construcción de una memoria artificial identitaria, probablemente no resultase conveniente seguir haciendo referencia a esas prácticas heterodoxas o a modificaciones en la implantación del catolicismo, prácticas y modificaciones que revelaban la inexistencia de un dominio jesuítico perfecto (Melai, 2010, 2011).

${ }^{53}$ Cardiel, 1913 [c. 1771]: 514.

${ }^{54}$ Merece destacarse que en la versión manuscrita de la Breve relación... que se encuentra en el ARSI, esta dedicatoria no existe (ARSI, Paraquaria, 14). Tampoco existe dedicatoria en el Compendio..., lo cual resulta lógico si se pretendió ocultar la autoría del mismo y presentarlo como un libro escrito por un cura secular.

${ }^{55}$ Cardiel, 1779: 561. La traducción de Hernández es: "La primera llegada de los españoles para colonizar el Río de la Plata, ocurrió hacia 1530” (Muriel, 1919: 463). 
las "Dudas" polémicas que eran respondidas al final de la Breve relación... En esas Dudas, se respondían, con abundantes referencias a los críticos anti-jesuíticos y a sus argumentos, preguntas como: “¿De dónde nace que los Padres son Obispos, y aun Papas, Gobernadores y Reyes?" o "De donde toman motivo para exagerar tanto las riquezas de aquellos pueblos [reducciones]...?"56.

La tercera diferencia es una modificación de la valoración respecto de la obra jesuítica entre los guaraníes. En la Breve relación... (también en la Carta y relación... de 1747, y en bastante menor medida en el Compendio... de 1780) es perceptible una valoración retóricamente construida a través de un topos repetido: el asombro producido por el desarrollo del cristianismo en las misiones, hiperbolizado a través de las lágrimas. Así, sobre el salmo Laudate pueri, que se cantaba en algunas misas:

En el Laudate, comienzan los tenores y demás músicos grandes con los clarines y chirimías, instando á los niños tiples: laudate pueri, pueri laudate, laudate nomen domini: repitiendo é instando que alaben á nuestro Dios. Comienzan los niños tiples: sit nomen domini benedictum, etc. etc., y después de algunos versículos vuelven los grandes á instar con devotísimo estruendo de instrumentos: pueri laudate nomen domini (No se maravillen si va mojado de lágrimas este papel) Vuelven á repetir que alaben á Dios; y esto hacen cuatro ó cinco veces hasta que se acaba el Psalmo. Al Gloria Patri... 57.

También, en la sección sobre fiestas y procesiones del capítulo VII:

Celébranse las tinieblas con la música, pero no se usan violines, sino violones y flautas de coro y espinetas, ó clavicordios, y en algunas partes liras, instrumento de arco muy dulce y sonoro y devoto, que en lo suave y grave imita algo al clavicordio. Al Miserere se azotan con un rigor singular. El Jueves Santo por la noche hay sermón de Pasión. Después empieza la procesión. Esta es tan devota, que no se puede explicar sin lágrimas. Es de este modo:

Previénense treinta y tantos niños de nueve á diez años con sotanas y muy decentes vestidos talares... ${ }^{58}$.

En cambio, obsérvese cómo se relata el salmo Laudate pueri en "De moribus...":

Laudate pueri incipiunt tenores, \& turba tubicinum, Laudate pueri, pueri laudate, laudate nomen Domini. Tunc pueri de choro triplicant: Sit nomen Domini benedictum, \&c. Post aliquot versiculos turba majorum instat: Pueri laudate, laudate pueri Dominum. Parvuli respondent: idque ter vel saepius. Ad Gloria Patri... 59 .

\footnotetext{
${ }^{56}$ Cardiel, 1913 [c. 1771]: 586. Como se ha señalado anteriormente, la Breve relación... contenía la explicación de las misiones a los indígenas que no eran guaraníes en esta sección de "Dudas". Dicha explicación, por lo tanto, fue suprimida en "De moribus...". Las "Dudas" no existen en la Carta y relación..., que de todos modos sí contiene secciones polémicas, mientras que en el Compendio... son reubicadas en el cuerpo del texto y no en una sección final.

${ }^{57}$ Ibíd., 1913 [c. 1771]: 559; subrayado en latín del texto, subrayado en castellano nuestro

${ }^{58}$ Ibíd.: 567.

${ }^{59}$ Ibíd., 1779: 571. La traducción es Hernández es: “Laudate pueri, empiezan los tenores, y la multitud de flautas repite Laudate pueri, pueri laudate, laudate nomen Domini. Entonces, unos niños del coro repiten: Sit nomen Domini benedictum, etc. Después de algunos versículos canta la muchedumbre de los adultos:
} 
Y, sobre la procesión de Jueves Santo, también en "De moribus...":

Pleno musicorum choro officia sanctioris hebdomadae celebrantur, adhibiris tantum gravioribus organis. Ad Miserere strepitus de more fit, sed flagris se verberamitum. Sermo de Passione fit per noctem die Jovis Sancto, quem prope sequitur supplicatio. Parantur triginta \& eo amplius pueri annorum novem aut decem, cum decoro vestitu talari... ${ }^{\circ}$.

¿Qué puede explicar estas modificaciones y supresiones? Todas ellas remiten a una intervención editorial destinada a eliminar las marcas de comunicación personal (como la dedicatoria, a pesar de que otros textos del apéndice mantienen su formato de carta), los signos de subjetividad del autor (como las lágrimas) y, por último, cualquier aspecto polémico. Sin embargo, esta intervención se realiza puntualmente sobre este texto en particular, y no necesariamente sobre otros que figuran antes o después del mismo. En este sentido, parece perceptible una intención de presentar a "De moribus..." como una fuente, una "prueba" documental, carente de partidismos, pasiones y subjetividad y completamente descriptiva, neutral y objetiva. Cardiel nunca había sido designado historiador oficial de la Provincia Jesuítica del Paraguay; las relaciones que él pudiera escribir, en principio, no necesariamente coincidían con los parámetros historiográficos y de sistematicidad de la orden. En este sentido, es bastante probable que la intervención editorial obedezca precisamente a la mano de Domingo Muriel, quien sí cumplió ese rol oficial.

Por lo demás, el uso, dentro del género historiográfico, de este texto como una fuente "neutral" probablemente guarde relación con una transformación en la historiografía jesuítica en particular y en los géneros textuales en general después de la expulsión de la orden de los dominios ibéricos ${ }^{61}$. En efecto, después de este hecho, como ya se ha dicho, los canales de interlocución de la escritura jesuítica variaron, y muchas obras pasaron a construirse como réplicas a las críticas anti-jesuíticas. Esta operación es particularmente evidente en las "historias naturales", pero también en textos como el mencionado de Peramás. Dada la modificación de la interlocución, los autores jesuitas debieron en muchas ocasiones sistematizar los conocimientos producidos, en el marco de polémicas en las que estaba en debate la veracidad y fundamentación de las afirmaciones y argumentos. Aunque aún es necesario profundizar en el conocimiento sobre cómo esta transformación influyó en los géneros historiográficos, puede inscribirse este "uso" subordinado de la obra de Cardiel como apéndice documental en la historia de Muriel en el marco de las nuevas necesidades de las polémicas "científicas"62.

Pueri laudate, laudate pueri Dominum. Los niños responden, y esto hacen tres o más veces. Al Gloria Patri..." (Muriel, 1919: 514).

${ }^{60}$ Cardiel, 1779: 574. La traducción es Hernández es: “Celébranse los oficios de Semana Santa con coro pleno de músicos, empleando sólo los órganos más graves. Al Miserere se hace ruido, pero es de penitentes que se azotan. El Sermón de Pasión se hace día de Jueves Santo a la noche, y luego se sigue la procesión. Previénense treinta o más niños de nueve a diez años, con conveniente vestido talar..." (Muriel, 1919: 526-527).

${ }^{61}$ Wilde, en prensa, b.

${ }^{62}$ Por lo demás, es cierto que existen testimonios de transformaciones más radicales que las que hemos señalado aquí en el pasaje de la escritura edificante jesuítica desde un formato de circulación presumiblemente reducida (como el manuscrito) a otro formato de circulación presuntamente más amplia (como el impreso). Por ejemplo, se ha señalado el intento por ocultar adaptaciones locales, referencias a religiones diferentes a la católica y alusiones negativas a los aliados geopolíticos (Hoyos, 2015: 96-106), es decir, los aspectos más netamente polémicos. Sin embargo, nada de eso fue necesario en "De moribus...": 


\section{c) Valoración de la conquista española y propaganda}

Aunque el Compendio... de 1780 es el único texto que, por su título, se presenta como una "historia", los otros libros, pese a ser formalmente cartas relatorias y relaciones, también incluyen secciones históricas referidas a acontecimientos que, cronológicamente, Cardiel no pudo presenciar. Es el caso de los episodios iniciales de la conquista y ocupación del territorio rioplatense por parte de los españoles, que en todos los textos se ubican en las primeras páginas, a manera de presentación. En esta región, los españoles fundaron un primer asentamiento en Buenos Aires en 1530, que al poco tiempo debió ser abandonado. El establecimiento en Asunción data de 1536. Especialmente en la región del Paraguay, los españoles sometieron a los indígenas al sistema de las encomiendas, como forma de extraer excedente a través del pago de tributos o de servicios personales. La Compañía de Jesús había llegado al Virreinato del Perú en la segunda mitad del siglo XVI; en el Paraguay, algunos jesuitas entraron en conflictos con los encomenderos en la medida en que la fundación de reducciones forzosamente determinaba una disminución del caudal de mano de obra indígena disponible. Los propios jesuitas llegaron a defender sus reducciones con, entre otros, argumentos centrados en los abusos cometidos por los encomenderos. Con respecto a este conflicto, en la Breve relación... puede leerse:

"[P]aró el punto en que los tributarios sirviesen personalmente al conquistador dos meses al año en lugar del tributo. A estos conquistadores llamaban encomenderos., y á los tributarios, mitayos, y al servir los dos meses, pagar la mita. Pero no se contentaron con los dos meses. Los más se hacían servir del mitayo todo el año, sin pagarle los diez meses: y el más escrupuloso, seis ó siete meses. Los Nuestros [jesuitas] en particular y en público en los pulpitos procedían con celo contra este impío abuso; y por ello fueron tan perseguidos que llegaron en algunas partes á echarlos de los colegios"63.

Referencias similares pueden leerse en la Carta y relación... y, con menos énfasis, en "De moribus...". En general, aparece enfatizado el rol jugado por los jesuitas en la defensa de los indígenas frente a los encomenderos, y especialmente frente al servicio personal. En términos discursivos, entonces, en estos textos los miembros de la Compañía de Jesús aparecen presentados casi como "lascasianos". Obsérvese otra alusión similar a la citada en la Breve relación..., en la que, de hecho, puede verse una referencia positiva hacia Bartolomé de Las Casas. Este fragmento no se ubica al comienzo del texto, sino en una de las "Dudas" polémicas que se responden al final del mismo:

"como los Nuestros [jesuitas] luego se ponen á defender los derechos de los pobres indefensos, asestan toda la batería contra ellos. Qué extorsiones, opresiones, vejaciones, no hicieron los de esta calidad [españoles codiciosos] contra los pobres indios desde los principios. Véase además del Obispo de Chiapa (que lo tienen por nimio), al Obispo de Santa Fe de Bogotá, Piedrahita, clérigo, y natural de aquellas partes. Véase (...)"64.

\footnotetext{
por razones que hemos explicado sobre todo en la sección anterior, y que no conciernen específicamente al formato de circulación del texto, la mayor parte de esas alusiones ya habían sido eliminadas en el pasaje de la Carta y relación... de 1747 a la Breve relación... de c. 1771.

${ }^{63}$ Cardiel, 1913 [c. 1771]: 515, subrayados originales.

${ }^{64}$ Ibíd.: 603; Las Casas fue obispo de Chiapas entre 1543 y 1546.
} 
Ahora bien, ¿qué dice el Compendio... respecto de este problema? La valoración sobre los encomenderos y conquistadores españoles se ha modificado sensiblemente. En este libro, la sección relativa a la historia de la conquista y ocupación del territorio rioplatense ha crecido en extensión y en carácter polémico. Así, sobre los conquistadores puede leerse:

"Muchos piensan (y aun lo escriben) que los españoles conquistadores de aquellos países entraban bárbaramente en ellos, asolando, destruyendo, quemando y matando. No fue así. Entraban siempre de paz, diciendo que eran vasallos de un gran Rey que los enviaba a aquellas tierras (...) Esto es lo que sucedía (...) no las crueldades de unos Nerones que pintan algunos mal informados o mal intencionados. Hasta el ya alabado Muratori [Ludovico Muratori, autor de El cristianismo feliz] exagera estas crueldades, no por mala intención, sino por mal informado en este punto" $"$.

Esta caracterización contrasta grandemente con el énfasis en el uso de las armas para el establecimiento del sistema de encomiendas y servicios personales en los otros textos. A su vez, la referencia positiva al "obispo de Chiapas" también se ha transformado:

"Alegan luego los enemigos de los conquistadores españoles el tomito que sacó a luz el señor Obispo de Chiapas, don Bartolomé de las Casas de las crueldades y excesos de sus paisanos los españoles en sus primeras conquistas. Este libro, dicen algunos que se ha averiguado ser forjado y añadido de extranjeros. Lo cierto es que, si hemos de creer a otros escritores harto verídicos de aquellos tiempos, hay mucho de exageración en él (...)"66.

En la Breve relación... se citaba aprobatoriamente a Las Casas, y en todo caso eran los adversarios quienes lo juzgaban "nimio". En cambio, en el Compendio... de 1780 es el propio autor del texto quien pasa a juzgarlo exagerado. ¿A qué se puede atribuir esta diferencia? La Corona española había expulsado de sus territorios a los jesuitas en 1767-1768, obligándolos a exiliarse en Italia. Más aún, desde entonces había presionado activamente a Roma para lograr la supresión papal de la Compañía, lo que se produjo en 1773. Sin embargo, nada de esto significó una ruptura completa en la relación entre España y los jesuitas. De hecho, fueron designados comisarios especialmente encargados de sostener una relación, ciertamente de control y disciplinamiento, con los jesuitas expulsos, quienes además recibían una escasa pensión para su sostenimiento económico básico. En este sentido, desde la expulsión misma existía una vigilancia sobre la producción intelectual de estos jesuitas, en busca, especialmente, de manifestaciones de "jesuitismo subversivo" que pudiesen justificar la quita individual de la pensión $^{67}$.

Ahora bien, después de 1773, el valor real de la pensión de los jesuitas empezó a decrecer debido a una tendencia inflacionista y a la ruptura, tras la expulsión, de la solidaridad entre las comunidades de la Compañía. En este contexto, se produce en 1777 el ascenso del conde de Floridablanca (1728-1808) como Secretario de Estado, cargo que ocuparía hasta 1792. En esta época, estaba en proceso una polémica anti-española, im-

\footnotetext{
${ }^{65}$ Ibíd., 1984 [1780]: 44.

${ }^{66}$ Ibíd.: 46.

${ }^{67}$ Melai, 2011: 54.
} 
pulsada entre otros hechos por la guerra de independencia de las colonias norteamericanas y fomentada por ilustrados italianos, franceses y escoceses, que cuestionaba, sobre todo, la conquista de América por sus perniciosas consecuencias humanas y económicas. Floridablanca decidió aprovechar la capacidad intelectual jesuítica y premiar con una pensión doble a aquellos jesuitas de las ex Provincias hispánicas que escribiesen textos en polémica con la crítica anti-española ${ }^{68}$. La delicada situación económica de los expulsos fue, de esta manera, hábilmente explotada por el gobierno de Carlos III.

Respecto de la escritura edificante jesuítica, Polanco postulaba en el siglo XVI evitar alusiones a la política o a aspectos que pudiesen ofender. En los primeros tres textos de Cardiel analizados, existen efectivamente algunas alusiones políticas, pero ocupan poco espacio y por lo general están en directa relación con el realce apologético de la Compañía de Jesús. Podría decirse, entonces, que aunque limitadamente esos textos no dejaban de cumplir la sugerencia de Polanco. Esto se modifica en el Compendio...: aquí las referencias políticas polémicas no relacionadas con la defensa de los jesuitas son abundantes, aunque no apuntan a ofender sino, precisamente, a defender a los españoles. El Compendio..., entonces, es una manifestación clara de la plegadura de los jesuitas expulsos hacia la campaña propagandística de Floridablanca. Su objetivo polémico, por lo demás, no puede ser entendido si no se tiene en cuenta la modificación de los interlocutores en la escritura jesuítica post-expulsión, que ya se ha mencionado anteriormente: aunque siguen inscribiéndose en la tradicional escritura edificante, muchos de estos textos empiezan a dialogar (a debatir) directamente con los ilustrados ${ }^{69}$, sea en su faceta de críticos anti-jesuíticos, sea en su carácter de críticos anti-españoles ${ }^{70}$. Esa interlocución, ese diálogo explican que Cardiel haya decidido ocultar su identidad autoral y firmar el Compendio... con un anagrama.

\section{Conclusión}

En resumidas cuentas, entre la Carta y relación... de 1747, la Breve relación... de c. 1771, "De moribus...", impreso en 1779 y el Compendio... de 1780, existen diferencias, modificaciones, supresiones y adiciones. En primer lugar, también entre la Carta y relación... de 1747 y los restantes textos, se modifican fuertemente o suprimen todas aquellas alusiones a prácticas pragmáticas y políticas de adaptación de los jesuitas en los contextos locales de misión. Estas supresiones se han explicado por la agudización de la polémica anti-jesuítica a lo largo del siglo XVIII, que en muchas ocasiones denunció precisamente el modo pragmático de proceder de la orden (tal es el caso, por ejemplo, del debate sobre los ritos chinos) y por la expulsión de los jesuitas del territorio de la Corona española (1767-1768) y su consiguiente exilio en Italia, hechos que determinaron un cambio en los interlocutores de la escritura edificante, a partir de entonces centrada en responder a los críticos ilustrados contrarios a la Compañía. Además, se ha

\footnotetext{
${ }^{68}$ Guasti, 2009, 2010. En cuanto al rol de los jesuitas expulsos como críticos de la polémica ilustrada antiespañola de fines del siglo XVIII, puede consultarse también Cañizares Esguerra (2007: 318-332), que se centra en los catalanes Juan de Nuix y Ramón Diosdado Caballero y focaliza, especialmente, en el aspecto argumentativo e historiográfico del debate.

${ }^{69}$ Wilde, en prensa, b.

${ }^{70} \mathrm{El}$ intento de responder las críticas anti-españolas en el Compendio... no lleva a abandonar las respuestas a las críticas anti-jesuíticas. De hecho, en este texto el relato del conflicto entre los jesuitas y el obispo Cárdenas de Asunción, en el siglo XVII, ocupa un espacio sensiblemente mayor que en los libros anteriores (Cardiel, 1984 [1780]: 146-185).
} 
señalado la posibilidad de que el uso de la historia de las misiones del Paraguay en la construcción de una memoria específica de los jesuitas expulsos de esa Provincia haya influido respecto de la necesidad de presentar una descripción de dichas reducciones como un espacio utópico sin imperfecciones ni prácticas polémicas. En segundo lugar, especialmente entre la Breve relación... y "De moribus...", se han identificado transformaciones editoriales que pretendieron convertir la relación de Cardiel en un texto neutral y objetivo, pasible de ser utilizado como un apéndice documental en la Historia Paraguajensis... de Charlevoix y Muriel. Asimismo, el uso (alterado) de un texto de Cardiel como fuente histórica - como "prueba" - se ha relacionado con las mutaciones de la escritura jesuítica después de la expulsión a partir del cambio ya mencionado de los interlocutores, y la consiguiente necesidad de una sistematización de los conocimientos producidos y una mayor fundamentación de los mismos. En tercer lugar, entre la redacción de los primeros textos y del último, se modifica la valoración de los conquistadores y encomenderos españoles. Para explicar esta variación, se han tenido en cuenta las dificultades económicas de los jesuitas expulsos y la política de Floridablanca de otorgar financiamiento a los mismos a cambio de la elaboración de textos que respondiesen a las críticas anti-españoles en auge entre los ilustrados en esos momentos.

En la primera sección de este texto se han explicado las diferencias entre, por un lado, escritura edificante y mostrable y, por el otro, escritura no mostrable. Los cuatro textos analizados se inscriben en la tipología de la escritura edificante. Sin embargo, respecto de esta escritura, el propio Ignacio de Loyola, en la carta de 1542, recomendaba la reescritura y corrección constante de las "cartas principales", con el objetivo de eliminar las impertinencias que no pudiesen ser leídas por un público amplio. "Remirar" y "hacer escribir" "otra vez" eran aspectos centrales de las recomendaciones y órdenes de Ignacio. En el siglo XVIII, la reescritura y la corrección de textos edificantes mantenían su importancia, pero la comparación entre las obras de Cardiel demuestra, también, que esas tareas no finalizaban una vez que el texto empezaba a circular, sino que se sostenían en el mediano plazo. Los libros sobre la Provincia Jesuítica del Paraguay firmados por o atribuidos a este autor, desde 1747 hasta su muerte, conformaron sendas reescrituras, correcciones, adiciones y supresiones sobre un texto de base. Estas correcciones y reescrituras no se hicieron en el "vacío", sino en estrecha dependencia de, por un lado, los violentos virajes en el contexto político y religioso en los años más convulsionados de toda la historia de la antigua Compañía de Jesús y, por el otro, del formato de circulación de los textos. En ese marco, los objetivos edificantes propios de la escritura mostrable jesuítica se sostuvieron, pero con un carácter más defensivo, con un acrecentamiento progresivo de aquellas referencias juzgadas "impertinencias" para no ser mostradas y, en un caso al menos, con una puesta de la escritura apologética al servicio no sólo de la Compañía de Jesús, sino también de la Corona española.

Tomando como base las ediciones citadas, la correspondencia entre los capítulos es, desde luego, sólo aproximada, y está dada por referencias y temas comunes. Hay secciones enteras que no tienen correspondencia entre sí. Los últimos capítulos de la Carta y relación... (X a XIII) relatan las misiones de la Provincia del Paraguay con indios diferentes a los guaraníes. Este contenido figura en la duda sexta del apéndice de la Breve relación... y en algunos párrafos del capítulo II del Compendio... En este Compendio... hay largos capítulos (XI a XIV) sobre la Guerra Guaranítica, que parcialmente se relata en el capítulo $\mathrm{V}$ de la Breve relación..., capítulo mayormente centrado en otros tópicos. Asimismo, el Compendio... incluye capítulos puntuales (XV a $\mathrm{XX}$ ) sobre el conflicto de los jesuitas con el obispo Cárdenas en el siglo XVII, sin correspondencia en otros textos. 
Anexo: correspondencias aproximadas entre los capítulos de los textos de Cardiel

\begin{tabular}{|l|l|}
\hline \multicolumn{2}{|c|}{ Tabla I } \\
\multicolumn{1}{|c|}{$\begin{array}{c}\text { Carta y relación... } \\
\text { (1747) }\end{array}$} & Dedicatoria \\
\hline Dedicatoria & Capítulos I y II \\
\hline Capítulo I & Capítulo III \\
\hline Capítulo II & Capítulo VI \\
\hline Capítulo III & Capítulo V \\
\hline Capítulos IV y V & Capítulo IV \\
\hline Capítulo VI & Capítulo VIII \\
\hline Capítulo VII & Capítulo VII \\
\hline Capítulo VIII & Capítulo VII \\
\hline Capítulo IX & \\
\hline Capítulos X a XIII & Dudas \\
\hline- &
\end{tabular}

\begin{tabular}{|c|c|}
\hline \multicolumn{2}{|c|}{ Tabla II } \\
\hline $\begin{array}{c}\text { Breve relación... } \\
\text { (c. 1771) }\end{array}$ & $\begin{array}{c}\text { Compendio... } \\
(\mathbf{1 7 8 0})\end{array}$ \\
\hline Dedicatoria & - \\
\hline- & Capítulo I \\
\hline Capítulos I y II & Capítulos II y III \\
\hline Capítulo III & Capítulos IV y V \\
\hline Capítulo IV & Capítulo IX \\
\hline Capítulo V & $\begin{array}{l}\text { Capítulos VI y XI a } \\
\text { XIV }\end{array}$ \\
\hline Capítulo VI & Capítulo VII \\
\hline Capítulo VII & Capítulo VIII y IX \\
\hline Capítulo VIII & Capítulo VIII \\
\hline Dudas & - \\
\hline- & Capítulo X \\
\hline- & Capítulos XV a XX \\
\hline
\end{tabular}

La correspondencia de los capítulos de la Breve relación... y "De moribus..." es más clara. Tomando en cuenta la edición original latina, los capítulos III, IV, V y VI de la Breve relación... corresponden, respectivamente, a los capítulos II, III, III bis (por un error de imprenta figuran dos capítulos III) y IV de "De moribus...". El capítulo VII de la Breve relación... incluye los contenidos de los capítulos VI, VII y IX. El capítulo "último" (VIII) de la Breve relación corresponde al VIII de "De moribus..."71 .

\section{Fuentes documentales}

AGN. Archivo General de la Nación (Buenos Aires, Argentina).

ARSI. Archivum Romanum Societatis Iesu (Roma, Italia).

\section{Referencias}

Arzubialde, S., Corella, J. y García Lomas, J. M. (Eds.) (1993). Constituciones de la Compañía de Jesús. Santander: Editorial Sal Terrae.

Becker, F. (1987). Un mito jesuítico. Nicolás I Rey del Paraguay. Asunción: Carlos Schauman Editor.

Cañizares Esguerra, J. Cómo escribir la historia del Nuevo Mundo: historiografías, epistemologías e identidades en el mundo del Atlántico del siglo XVIII. México D. F.: Fondo de Cultura Económica, 2007.

Caraman, P. (2001). “Cardiel, José. Misionero, escritor, cartógrafo". En O’Neill S.I., C. y Domínguez S.I., J. M. (Dir.) (2001). Diccionario histórico de la Compañía de Jesús.

\footnotetext{
${ }^{71}$ La edición castellana de Hernández corrigió el error respecto de la numeración de los capítulos III, que pasaron a ser III y IV, modificando la numeración de los capítulos siguientes, pero incluyó otro error al numerar dos capítulos como VII, que se corresponden con los capítulos VI y VII de la edición latina.
} 
Biográfico-temático (volumen I). Roma-Madrid: Institutum Historicum Societatis Iesu/Universidad Pontificia Comillas, 654-655.

Cardiel, J. (1953 [1747]). “Carta y relación de las misiones de la provincia del Paraguay”. En Furlong, G. José Cardiel S. J. y su Carta-Relación (1747). Buenos Aires: Ediciones Librería del Plata, 1953, 115-216.

— (1913 [c. 1771]). "Breve relación de las Misiones del Paraguay". En Hernández, P. Organización social de las doctrinas guaraníes de la Compañía de Jesús (Tomo II). Barcelona: Gustavo Gili, 514-614.

— (1779). "De moribus guaraniorum". En Historia Paraguajensis Petri Francisci-Xavierii de Charlevoix, ex Gallico Latina, cum animadversionibus et supplemento. Venetis: Apud Franciscum Sansoni. 561-578.

(1984 [1780]). Compendio de Historia del Paraguay. Estudio preliminar de J. M. Mariluz Urquijo. Buenos Aires: Fundación para la Educación, la Ciencia y la Cultura.

Chinchilla, P., Correa, L. y Mendiola, A. (2008). "La construcción retórica de la realidad: la Compañía de Jesús”. Historia y Grafía. México D. F., 30, 135-164.

Corsi, E. (2008). "El debate actual sobre el relativismo y la producción de saberes en las misiones católicas durante la primera Edad Moderna: ¿una lección para el presente?’. En Corsi, E. (Coord.). Órdenes religiosas entre América y Asia. Ideas para una historia misionera de los espacios coloniales. México D. F.: El Colegio de México, 17-54.

Delumeau, J. (1992). La confesión y el perdón. Las dificultades de la confesión, siglos XIII a XVIII. Madrid: Alianza Editorial.

Fechner, F. (2014). "Las tierras incógnitas de la administración jesuita: toma de decisiones, gremios consultivos y evolución de normas". En Histórica. Lima, XXXVIII, 2, 11-42.

Fechner, F. (2015). "Un discurso complementario sobre la posición jurídica de la población indígena colonial: las congregaciones provinciales en la provincia jesuítica del Paraguay (1608-1762)”. En Köhler, R. y Ebert, A. (Eds.). Las agencias de lo indígena en la larga era de la globalización. Microperspectivas de su producción y representación desde la época colonial temprana hasta el presente. Berlín: Gebr. Mann Verlag, 99-118.

"Formula scribendi auctoritate tertiae Congregationis generalis confecta" (1966 [1573]). En Monumenta Missionum Societatis Iesu, vol. XXI, Missiones Orientales, Documenta Indica, IX (1573-1575), Romae: Monumenta Historica Soc. Iesu., 236-239.

Friedrich, M. (2008). "Circulating and Compiling the Litterae Annuae. Towards a History of the Jesuit System of Communication". Archivoum Historicum Societatis Iesu. Roma, 153, LXXVII, 3-40.

Furlong, G. (1953). José Cardiel, S.J. y su Carta-Relación (1747). Buenos Aires, Ediciones Librería del Plata.

Ginzburg, C. (2014). "Aún sobre los ritos chinos: documentos viejos y nuevos”. En Undurraga, V. y Gaune, R. (Eds.). Formas de control y disciplinamiento. Chile, América y Europa, siglos XVI-XIX. Santiago de Chile: Uqbar/Pontificia Universidad Católica de Chile/Instituto Riva-Agüero, 301-315. 
Guasti, N. (2009). "Rasgos del exilio italiano de los jesuitas españoles". Hispania Sacra. Madrid, LXI, 123, 257-278.

(2010). "Il tema americano nelle strategie culturali dei gesuiti spagnoli espulsi”. En Ugo Baldini y Gian Paolo Brizzi (cur.). La presenza in Italia dei gesuiti iberici espulsi. Aspetti religiosi, politici, culturali. Bologna: CLUEB, 411-449.

Hernández, P. (1913). Organización social de las doctrinas guaraníes de la Compañía de Jesús (Tomo II). Barcelona: Gustavo Gili.

Hoyos Hattori, P. (2015). "Políticas editoriales en las cartas jesuitas de Japón (Évora, 1598): análisis de tres epístolas". Anuario de la Escuela de Historia Virtual. Córdoba, 6, 8, 90-109.

Ignacio de Loyola (1903a [1542]). "[Carta a] Patri Petro Fabro, 10 Decembris 1542”. En Monumenta Ignatiana ex Autographis vel ex Antiquioribus Exemplis Collecta. Series Prima, Tomus Primus. Matriti: Typis Gabrielis Lopez del Horno, 236-239.

(1903b [1543]). "[Carta a] Patri Nicolao Bobadille, Roma [incerto mense et die 1543]". En Monumenta Ignatiana ex Autographis vel ex Antiquioribus Exemplis Collecta. Series Prima, Tomus Primus. Matriti: Typis Gabrielis Lopez del Horno, 277-282.

Imolesi, M. E. (2004). "Menos averigua Dios y perdona. Los jesuitas y el matrimonio indígena". Entrepasados. Buenos Aires, 13, 26, 105-126.

(2012). Teoría y práctica de la cristianización del matrimonio en Hispanoamérica colonial. Buenos Aires: Facultad de Filosofía y Letras, Universidad de Buenos Aires.

Justo, M. de la S. (2013). “Que no es todo para todos'. El deber de escribir en la Compañía de Jesús". Actas y Comunicaciones del Instituto de Historia Antigua y Medieval. Buenos Aires, 9.

Mariluz Urquijo, J. M. (1984). "Estudio preliminar". En Cardiel, J. Compendio de Historia del Paraguay. Estudio preliminar de José María Mariluz Urquijo. Buenos Aires: Fundación para la Educación, la Ciencia y la Cultura, 7-36.

Melai, F. (2010). "Elementi di una ricerca sulla mitologia e la sociologia dei Gesuiti Paraguaiani in esilio in Italia (1767-1814)". En AA. VV. Evangelizzazione e globalizzazione. Le missioni gesuitiche nell'etá moderna tra storia e storiografia. Roma: Societá Editrice Dante Alighieri, 61-78.

(2011). "La figura di Domingo Muriel nella crisi della Provincia Gesuitica del Paraguay (1750-1773)". Ricerche di Storia Sociale e Religiosa, A. XL, 80, luglio-dicembre, 3556.

Mignolo, W. (1992). "Cartas, crónicas y relaciones del descubrimiento y la conquista". En Madrigal, L. I. (Coord.). Historia de la literatura hispanoamericana (tomo 1). Madrid: Ediciones Cátedra, 57-102.

McNaspy, C. J. (2001). "Nusdorffer (Nusdorf, Nusderffer), Bernardo. Superior, misionero". En O’Neill S.I., C. y Domínguez S.I., J. M. (Dir.) (2001). Diccionario histórico de la Compañía de Jesús. Biográfico-temático (volumen III). Roma-Madrid: Institutum Historicum Societatis Iesu/Universidad Pontificia Comillas, 2842.

Montiel Contreras, C. U. (2014). "Escritura Ignaciana y 'cosecha javeriana' del P. Mayr en la Misión de Moxos”. IHS. Antiguos jesuitas en Iberoamérica, Córdoba, 2, 2, 4-24. 
Morales, M. M. (2007). "El arte se me ha perdido. Aproximaciones a la historiografía jesuítica”. Historia y Grafía. México D.F.: 29, 17-56.

(2011). "La respiración de ausentes. Itinerario por la escritura jesuítica". En Wilde, G. Saberes de la conversión. Jesuitas, indígenas e imperios coloniales en las fronteras de la cristiandad. Buenos Aires: Editorial SB, 31-59.

Muriel, D. (1919 [1779]). Historia del Paraguay desde 1747 hasta 1767. Obra latina del P. Domingo Muriel de la Compañía de Jesús, traducida al castellano por el P. Pablo Hernández de la misma Compañía. Madrid: Librería General de Victoriano Suárez.

Palomo, F. (2005). "Corregir letras para unir espíritus. Los jesuitas y las cartas edificantes en el Portugal del siglo XVI". Cuadernos de Historia Moderna. Anejos. Madrid, 4, 5781.

(2013). "Cultura religiosa, comunicación y escritura en el mundo ibérico de la Edad Moderna”. En Serrano, E. (Coord.). De la tierra al cielo. Líneas recientes de investigación en Historia Moderna. Zaragoza: Institución "Fernando el Católico" (CSIC), 53-88.

Pavone, S. (2014). "El antijesuitismo, la antigua y la nueva Compañía de Jesús. Nuevas perspectivas de investigación”. En Monreal, S., Pavone, S. y Zermeño, G. (Coord.). Antijesuitismo y filojesuitismo. Dos identidades ante la restauración. México D. F./Bogotá: Pontificia Universidad Javierana/Universidad Iberoamericana, 27-49.

Polanco, J. de (1903 [1547]). "Pater Joannes de Polanco ex Comm. Universae Societati Jesu, Roma 27 Julii 1547”. En Monumenta Ignatiana ex Autographis vel ex Antiquioribus Exemplis Collecta. Series Prima, Tomus Primus. Matriti: Typis Gabrielis Lopez del Horno, 536-549.

Rico-Callado, F. L. (2012). "La práctica de la confesión en la España moderna a través de la actividad de las órdenes religiosas". Studia historica. Historia moderna. Salamanca, 34, 305-332.

Rubiés, J. P. (2005). "The Concept of Cultural Dialogue and the Jesuit Method of Accommodation: Between Idolatry and Civilization". Archivium Historicum Societatis Iesu. Roma, 74, 147, 237-280.

Wilde, G. (2009). Religión y poder en las misiones de guaraníes. Buenos Aires, Editorial SB.

— (en prensa, a). "Writing Rites in the Borderlands: Appropriation, Mimesis and Interaction between Jesuits and Indians in Colonial South America". En Zupanov, I. G. y Fabre, P.-A. (Eds.) The Rites Controversy in the Early Modern World. Leiden: Brill.

— (en prensa, b). "Invención, circulación y manipulación de clasificaciones en los orígenes de una antropología misionera". En Giudicelli, C. (Comp.). La sociedades indígenas entre clasificaciones y memorias colectivas. Rosario: Editorial Prohistoria.

Zupanov, I. G. (2011). "El repliegue de lo religioso: misioneros jesuitas en la India del siglo XVII, entre la teología cristiana y la ética pagana". En Wilde, G. (Ed.). Saberes de la conversión. Jesuitas, indígenas e imperios coloniales en las fronteras de la cristiandad. Buenos Aires, Editorial SB, 505-532. 